\title{
Randomised trial of inhaled steroids in preterm infants with respiratory symptoms at follow up
}

\author{
B Yuksel, A Greenough
}

\begin{abstract}
Background Preterm infants often suffer from recurrent respiratory symptoms at follow up. Although these infants are responsive to treatment with bronchodilators some continue to wheeze or cough despite treatment. In a randomised double blind placebo controlled trial, the ability of inhaled steroids to reduce recurrent respiratory symptoms and the requirement for bronchodilator treatment in preterm infants less than two years of age has been assessed.

Methods Eighteen premature infants with mean gestational age 28 weeks and postnatal age 10.5 months were recruited. The study consisted of two six week treatment periods separated by a two week washout period. The infants received either $200 \mu \mathrm{g}$ of beclomethasone dipropionate or placebo as one puff twice daily from an inhaler, through a spacer and a face mask. Parents kept a daily record of their infants' respiratory tract symptoms (wheeze and cough) and use of bronchodilators. Functional residual capacity (FRC) was measured at the beginning and end of each six week period.
\end{abstract}

Results The symptom score was reduced by $37 \%$ in the active compared with the placebo period. During the active period the infants had a mean of 28 bronchodilator free days, compared with 22 days in the placebo period. The FRC improved significantly in the active but not the placebo period.

Conclusion Regular dosage with beclomethasone by inhalation is a useful treatment for preterm infants with respiratory symptoms.

(Thorax 1992;47:910-913)

Preterm infants have increased respiratory morbidity at follow up compared with those born at term. ${ }^{1}$ They suffer from recurrent respiratory symptoms that are associated with abnormalities of lung function indicative of gas trapping ${ }^{2}$ and they have more admissions to hospital. ${ }^{3}$ It seems likely that these infants suffer from a type of asthma, particularly as they are responsive to inhaled ${ }^{45}$ and nebulised $^{67}$ bronchodilators. Despite such treatment, however, some continue to wheeze and cough with or without respiratory infections. Topical corticosteroids are now widely used in childhood asthma with benefit and minimal side effects. ${ }^{8}$ Beclomethasone dipropionate has been shown to reduce symptoms in children younger than three years, ${ }^{9}$ but has not been assessed in infants born prematurely. The aim of this study was to determine the usefulness of regular inhaled beclomethasone in very young children born prematurely and with recurrent respiratory symptoms at follow up.

\section{Patients and methods}

Infants were eligible for entry into this randomised, double blind, placebo controlled, crossover study if they continued to show symptoms (wheeze or cough for at least four days a week) despite regular use of bronchodilators. All of the infants had received bronchodilator treatment at least three times a week and were entered into the study only if their symptoms were not controlled by this treatment given daily for a two week period. No infant had received inhaled steroids before entry into the study. The study was divided into two six week treatment periods separated by a two week washout period. The infants received in random order either active $(200 \mu \mathrm{g}$ beclomethasone dipropionate) or placebo treatment as one puff twice daily from an inhaler, through a spacer device and a face mask. The parents and the researcher who analysed the data on lung function and diary cards were blind to the order in which the treatments were given.

Parents completed a diary card in each of the six week periods on the frequency and nature of their infant's respiratory symptoms-namely, daytime and night time cough and wheeze. Each symptom category was scored 0-3 (no symptoms 0 , mild 1 , moderate 2 , bad 3 ), giving a maximum score of $\mathbf{5 0 4}$ for respiratory tract symptoms for each six week period. During the study parents were asked to continue their infant's treatment with inhaled bronchodilator at the usual dose until the infant had been symptom free for 24 hours and to restart if the infant again developed symptoms. The previously prescribed bronchodilator treatment was used, as necessary, throughout the study. The bronchodilator was administered from an inhaler via a spacer device and face mask; this delivery system was used because of the very young age of the patients. The parents recorded the number of days in each six week period that the bronchodilator was used.

At the beginning and end of each six week period, a clinical history was taken, the child was examined, and height, weight, and lung function were measured. Lung function was assessed by measurement of functional residual 
Table 1 Characteristics of patients

\begin{tabular}{|c|c|c|c|c|c|c|c|}
\hline $\begin{array}{l}\text { Patient } \\
\text { No }\end{array}$ & $\begin{array}{l}\text { Gestational } \\
\text { age (weeks) }\end{array}$ & $\begin{array}{l}\text { Birthweight } \\
(\mathrm{g})\end{array}$ & $\begin{array}{l}\text { Postnatal } \\
\text { age (months) }\end{array}$ & $\begin{array}{l}\text { Order of } \\
\text { treatment }\end{array}$ & $\begin{array}{l}\text { Duration of } \\
\text { ventilation } \\
\text { (days) }\end{array}$ & $\begin{array}{l}\text { Duration of } \\
\mathrm{O}_{2} \text { requirement } \\
\text { (days) }\end{array}$ & $\begin{array}{l}\text { Family history } \\
\text { of asthma }\end{array}$ \\
\hline 1 & 26 & 760 & 6 & $\mathbf{P}$ & 1 & 4 & + \\
\hline 2 & 25 & 550 & 20 & B & 3 & 8 & - \\
\hline 3 & 34 & 1020 & 15 & $\mathbf{P}$ & 0 & 1 & - \\
\hline 4 & 29 & 1582 & 10 & B & 2 & 4 & + \\
\hline 5 & 28 & 1080 & 9 & $\mathbf{P}$ & 4 & 14 & - \\
\hline 6 & 24 & 660 & 16 & $\mathbf{P}$ & 35 & 125 & - \\
\hline 7 & 29 & 1142 & 9 & B & 30 & 75 & - \\
\hline 8 & 34 & 1800 & 3 & B & 0 & 0 & + \\
\hline 9 & 34 & 1467 & 6 & $\mathbf{P}$ & 0 & 1 & - \\
\hline 10 & 28 & 1290 & 13 & $\mathbf{P}$ & 6 & 32 & - \\
\hline 11 & 25 & 816 & 24 & B & 7 & 35 & - \\
\hline 12 & 26 & 840 & 6 & $\mathbf{P}$ & 14 & 46 & - \\
\hline 13 & 34 & 1900 & 8 & B & 0 & 0 & - \\
\hline 14 & 26 & 640 & 5 & $\mathbf{P}$ & 12 & 48 & - \\
\hline 15 & 27 & 1138 & 14 & $\mathbf{P}$ & 3 & 10 & - \\
\hline 16 & 27 & 1236 & 10 & B & 9 & 48 & - \\
\hline 17 & 26 & 870 & 7 & $\mathbf{P}$ & 27 & 90 & + \\
\hline 18 & 27 & 1223 & 7 & B & 18 & 78 & + \\
\hline
\end{tabular}

P-Placebo then beclomethasone dipropionate; B-beclomethasone dipropionate then placebo; +-present; - -absent.

capacity (FRC) with a helium gas dilution technique previously described in detail. ${ }^{4}$ An increase in FRC was taken to indicate improvement because in our previous studies an increase in FRC has been associated with a reduction in symptoms. ${ }^{451011}$ To assess the repeatability of measurements of FRC, it was measured in 34 children of similar gestational and postnatal age as the study group at the beginning and end of a two week period. In 30 of the infants FRC was remeasured four weeks later. They all had no respiratory symptoms and none had received bronchodilator treatment at the time of the measurement. The coefficient of repeatability was calculated according to the method of Bland and Alt$\operatorname{man}^{12}$; for two weeks it was $15 \mathrm{ml}(2.3 \mathrm{ml} / \mathrm{kg})$ and for six weeks it was $18 \mathrm{ml}(2 \cdot 6 \mathrm{ml} / \mathrm{kg})$.

\section{TRIAL SIZE}

Using results derived from 30 children previously under our clinical care we calculated that a trial population of 18 children receiving both treatments in random order was necessary to detect with $80 \%$ power at the $5 \%$ level a significant difference of five days in bronchodilator use between the two treatments and a $33 \%$ reduction in the symptom score from the placebo to the active period.

\section{THE PATIENTS}

Twenty five infants were recruited. Seven infants did not complete the study, three failed to attend for follow up appointments and the respiratory state of four children deteriorated and for these we had to break the trial code. In

Table 2 Changes in symptom score and use of bronchodilator

\begin{tabular}{|c|c|c|c|c|}
\hline & \multicolumn{2}{|c|}{$\begin{array}{l}\text { Respiratory tract symptoms } \\
\text { (wheeze and cough) }\end{array}$} & \multicolumn{2}{|c|}{ Bronchodilator use (days) } \\
\hline & Placebo & $\begin{array}{l}\text { Beclomethasone } \\
\text { dipropionate }\end{array}$ & Placebo & $\begin{array}{l}\text { Beclomethasone } \\
\text { dipropionate }\end{array}$ \\
\hline $\begin{array}{l}\text { Mean } \\
\text { Median } \\
\text { Range }\end{array}$ & $\begin{array}{l}162 \\
156 \\
(56-269)\end{array}$ & $\begin{array}{l}103 \\
102 \\
(13-222)\end{array}$ & $\begin{array}{l}20 \\
20 \\
(9-30)\end{array}$ & $\begin{array}{l}14 \\
13 \\
(7-28)\end{array}$ \\
\hline
\end{tabular}

all four infants this occurred during the placebo period. Thus none of the seven infants failed to complete the study owing to their inability to tolerate the corticosteroid. Eighteen infants (nine boys and nine girls) completed the study. They had a mean birth weight of $1112 \mathrm{~g}$ (median 1109 (range 550-1900) g), a mean gestational age of 28 weeks (median 27 (range 24-34) weeks), and mean postnatal age at recruitment of 10.5 months (median nine (range 3-24)) months (table 1). All the infants had respiratory symptoms and were receiving treatment with bronchodilators. Seven children were receiving salbutamol, six terbutaline, and nine ipratropium bromide. Nine infants had had neonatal chronic lung disease, but only one had classical bronchopulmonary dysplasia. ${ }^{13}$ None of the infants was oxygen dependent or taking diuretics at the time of entry into the study. Five infants had a positive family history of asthma or atopy, or both.

This study was approved by the King's College Hospital ethics committee.

ANALYSIS

Differences between the placebo and active period were assessed for statistical significance by a two sided paired Student's $t$ test. The confidence intervals were then calculated with the appropriate $p$ value from the standard error of the difference of the means of the group. The results were also examined to assess whether there was a period or an order effect.

\section{Results}

The respiratory tract symptoms significantly decreased in the active compared with the placebo period (103 $v 162,95 \%$ confidence interval $(95 \% \mathrm{CI})$ of difference between means 24.1 to $92.9 ; \mathrm{p}<0.001)$. Infants tended to become symptom free towards the end of the active period. The difference represented a $37 \%$ improvement in the symptom score (table 2). No significant period or order effect was shown.

The use of bronchodilator treatment significantly decreased in the active compared 
with the placebo period $(13 \cdot 7 v 20 \cdot 2$ days, $95 \%$ CI of difference between means $3 \cdot 15$ to $9 \cdot 85$; $\mathrm{p}<0.001)$. The mean decrease in bronchodilator usage was $32 \%$ (table 2 ).

The figure shows the results for measurements of FRC. Baseline FRC did not differ significantly at the start of the two six week periods $(29.7 \mathrm{ml} / \mathrm{kg}$ for active period $v 31$ $\mathrm{ml} / \mathrm{kg}$ for placebo period, $95 \% \mathrm{CI}$ of difference between means $-2 \cdot 13$ to $4 \cdot 63$ ). There was no significant change in FRC over the placebo period ( $31 v 32 \mathrm{ml} / \mathrm{kg}, 95 \% \mathrm{CI}$ of the difference between means $-4 \cdot 6$ to $2 \cdot 3$ ). Over the active period FRC significantly increased ( $30 v 36 \mathrm{ml} /$ $\mathrm{kg}, 95 \% \mathrm{CI}$ of difference between means 2.9 $10 \cdot 1 ; \mathrm{p}<0 \cdot 002)$.

No child developed oral candidiasis during the study.

\section{Discussion}

Beclomethasone given regularly by inhalation reduced wheeze and cough in our study population of very young children. Bisgaard $e t$ $a l^{9}$ also found that inhaled steroids improved wheeze, sleep disturbance, and patient wellbeing. They, however, studied children born at term and not infants born prematurely as in our trial, and their patients were older, with a mean age of 24 months compared with 11 months in the present study.

Use of bronchodilators was reduced in the active compared with the placebo period. Throughout the trial, parents were instructed to use the same bronchodilator treatment as that previously prescribed for their child. Thus differences in the type of additional medication received by an individual infant did not occur to bias our results. In adults reduction in the use of bronchodilators has also been associated with maintenance inhaled steroid treatment. ${ }^{14}$ In children, inhaled corticosteroids reduce bronchial reactivity to methacholine $^{15}$ and in adults they reduce reactivity to eucapnic hyperventilation, exercise, and histamine. ${ }^{16}$
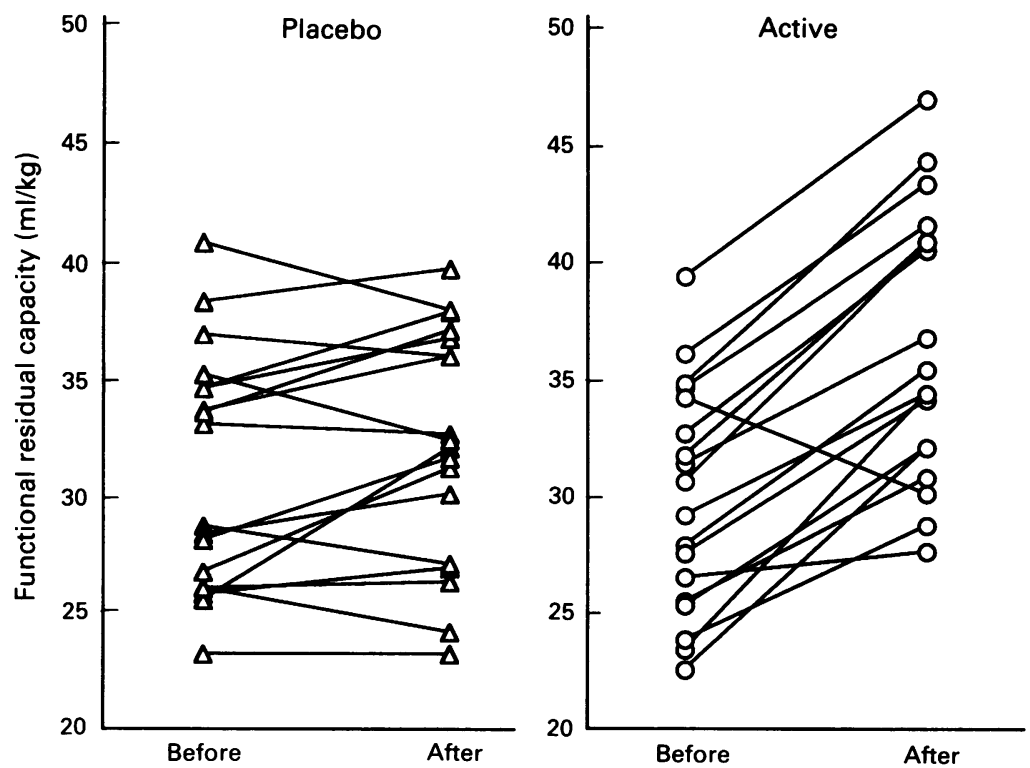

Functional residual capacity before and after placebo (left) and active treatment (right). Individual children's results are displayed by linked data points.
Such an effect may be responsible for the reduction in the use of bronchodilators seen in our trial population.

There has been concern that inhaled steroids may affect growth in asthmatic children. ${ }^{17}$ although this has been disputed. ${ }^{18} 19$ In our study steroids were inhaled for only six weeks; thus it is not possible for us to comment on that possible side effect. Other researchers have noted that use of inhaled steroids has been associated with an increase in oral candidiasis. ${ }^{20}$ This was not seen in the present study, or in a previous trial with school children. ${ }^{21}$

Lung function, assessed by measurement of FRC, a technique well tolerated in infants and very young children, ${ }^{41011}$ significantly increased over the six week active period, but there was no significant change over the placebo period. An improvement in lung function was defined as an increase in FRC. We considered this to be a reasonable definition as, among asthmatic children aged between two and five years, a decrease in symptoms was associated with an increase rather than a decrease in FRC. ${ }^{11}$ A similar association was also found in two trials of bronchodilator treatment in very young children. ${ }^{45}$ The measured FRC is dependent on the accessibility of helium to the lung compartments and thus our results must be explained by an improvement in this accessibility due to treatment with beclomethasone, with a consequent reduction in gas trapping and hence an increase in FRC.

We conclude that regular inhaled beclomethasone given via a spacer device and a face mask is a useful treatment for preterm infants persistently showing respiratory symptoms at follow up. This treatment, however, has potential side effects ${ }^{17}{ }^{20}$ and thus its use in preterm infants should be carefully monitored.

1 Bowman E, Yu V. Continuing morbidity in extremely low birthweight infants. Early Hum Dev 1989;18:165-74.

2 Yuksel B, Greenough A. Relationship of symptoms to lung function abnormalities in preterm infants at follow-up. Pediatr Pulmonol 1991;11:202-6.

3 Greenough A, Maconochie I, Yuksel B. Recurrent respiratory symptoms in the first year of life following preterm delivery. J Perinat Med 1990;18:489-94.

4 Yuksel B, Greenough A, Maconochie I. Effective bronchodilator therapy by a simple spacer device for wheezy premature infants in the first two years of life. Arch Dis Child 1990;65:782-5.

5 Yuksel B, Greenough A. Ipratropium bromide in symptomatic preterm infants. Eur J Pediatr 1991;150:854-7.

6 Yuksel B, Greenough A. Effect of nebulised salbutamol in preterm infants during the first year of life. Eur Resp $J$ preterm infants

7 Yuksel B, Greenough A, Green S. Paradoxical response to nebulised ipratropium bromide in preterm infants. Respir nebulised ipratropium

$8 \mathrm{Kerribijn} \mathrm{KF}$. Use of topical corticosteroids in the treatment of childhood asthma. Am Rev Respir Dis 1990;141:577-81.
Bisgaard H, Munck SL, Nielsen JP, Petersen W, Ohlsson Bisgaard H, Munck SL, Nielsen JP, Petersen W, Ohlsson
SV. Inhaled budesonide for treatment of recurrent wheezing in early childhood. Lancet 1990;336:649-51.

10 Yuksel B, Greenough A. Inhaled sodium cromoglycate for preterm children with respiratory symptoms at follow-up. Respir Med 1992;86:131-4.

11 Greenough A, Pool JB, Price JF. Changes in functiona residual capacity in response to bronchodilator therapy mong young asthmatic children. Pediatr Pulmonol 1989;7:8-11.

12 Bland $M$, Altman D. Statistical methods for assessing agreement between two methods of clinical measurement. Lancet 1986;i:307-10.

13 Northway WH, Rosan RC, Porter DY. Pulmonary disease following respiratory therapy of hyaline membrane disease. N Engl J Med 1967;276:357-68. 
14 Juniper EF, Kline PA, Vanzielegham MA, Ramsdale EH, O'Byrne PM, Hargreave FE. Long term effect of budesonide on airway responsiveness and clinical asthma severity in inhaled steroid-dependent asthmatics. Eur Respir J 1990;3:1122-7.

15 Kerrebijn KF, Essen-Zandvliet EEM, Neijens HJ. Effect of long term treatment with inhaled corticosteroids and betalong term treatment with inhaled corticosteroids and betaagonists on the bronchial responsiveness in child
asthma. J Allergy Clin Immunol 1987;79:653-9.

16 Vatheven AS, Knox AJ, Wisniewski A, Tattersfield AE. Effect of budesonide on bronchial reactivity to histamine, exercise and eucapnic dry air hyperventilation in patients with asthma. Thorax 1991;46:811-6.

17 Littlewood JM, Johnson AW, Edwards PA, Littlewood AE.
Growth retardation in asthmatic children treated with beclomethasone dipropionate. Lancet 1988; i:115-6.

18 Koenig $\mathrm{P}$. The role of inhaled steroids in the treatment of asthma. Respir Med 1989;83(suppl):43-7.

19 Varsano I, Volovitz B, Malik H, Amir Y. Safety of 1-year of treatment with budesonide in young children with asthma. J Allergy Clin Immunol 1990;85:914-20.

20 Toogood JH, Jennings B, Baskerville J, Anderson J, Johansson SA. Dosing regimen of budesonide and occurrence of oropharyngeal complications.

21 Gleeson JGA, Price JF. Controlled trial of budesonide given by the nebuhaler in pre-school children with asthma. BMJ 1988;297:163-6.

\section{Adventitia}

\section{A sabbatical year in England}

At the end of August 1973 I arrived in London for a sabbatical year at the Brompton Hospital. Home was then the Veterans Administration Hospital, Cleveland, Ohio, and the Medical School of Case Western Reserve University. My choice of the Brompton was based on rumours, then afoot in the medical world of America, that the Brompton was the best pulmonary disease centre in the world. I was to form a clear opinion by the end of my adventure!

My official host was Kenneth Citron, who had invited me after a visit of his to the United States, and in his diffident way introduced me to the world of English clinical medicine. His ward round was carried out in low key, typical of Kenneth, and each patient's chart was reviewed in great detail. This was followed by a bedside visit to each patient by all of those participating. Thus was the form and substance of the ward round with each of the clinicians with whom I spent time. And quite a list it was: Margaret Turner-Warwick, Neville Oswald, Margaret Branthwaite, Philip Zorab, John Batten, and Jack Pepys. In addition, I had remarkably informative encounters with Guy Scadding, who had recently retired but was often present; Stuart Lennox, whose surgical consultations were pithy and spare of fluff; and George Simon, whose flare and talent for teaching radiology, and more, excited the registrars, house physicians, and one very impressed American visitor.

In the pathology laboratory I encountered KFW Hinson and Brian Heard, and in the research area were Lynn Reid, who had captivated me (along with most of the chest medicine community of the United States) several years before, and Donald Mitchell, a legend for his unique approaches to problems of granulomatous diseases, whose Yorkshire accent was difficult to fathom for these inexperienced American ears. About each of these personalities I have bright and shining recollections that must remain unspoken owing to constraints of space.

The physical plant was, to an American of the time, shabby beyond belief. On close inspection, however, I discovered that the place was spotless, and wherever possible fresh paint had been applied and laboratories had been assembled in the relatively recently built Cardiothoracic Institute. As I browsed about the place I discovered that the "new wing" had been dedicated in the year that Koch announced the discovery of the tubercle bacillus, 1882 . The original hospital, still very functional, was opened in 1848. At that time London was more than 800 years old and Cleveland was still a collection of small Native American dwellings with few settlers in what was then called the Western Reserve of Connecticut. The tunnel connecting the two main buildings had a rise in the middle and a legend of having been traversed by pipes whose insulation had been crysotile until this was removed some few years before. I invariably used the tunnel with some trepidation, but the traffic of Fulham Road weighted the risk-benefit ratio in favour of the passageway.

My days were spent at the bedside with the above staff, browsing in the laboratories and the library, lunching in the pubs nearby or in the lounge in the institute, where white coats were left outside along with most things medical. I learned to solve the problems of the world with my hosts over biscuits, sandwiches, and juice, leaving the patients to their own devices for the half hour or so we all took. Morning coffee and afternoon tea were highest priority items. The biscuits, as always in London, were wonderful.

Who was the most important person I encountered during that sabbatical? None of the above. It was Cathy Ambrose, officially the secretary to the dean but admittedly the lynchpin of the entire operation. She saw to it that events came off on time and that the proper sherry was available when it was indicated. Her smile greeted me every day when I entered her office, where by chance I hung my hat. Cathy kept contact for many years after I left. I was not her only beneficiary. "No" was not in her vocabulary and she didn't even know how to spell "frown."

It was a fabulous year in which I learned (a) much about clinical medicine, (b) that English is different in England, and (c) that the Brompton Hospital was the best chest disease centre in the world!-GERARD L BAUM 